\title{
LAS EMOCIONES EN EL PROCESO DE PAZ COLOMBIANO
}

\section{EMOTIONS IN THE COLOMBIAN PEACE PROCESS}

\author{
Diana Carolina Valencia-Tello \\ Universidad del Rosario - Bogotá (Colombia)
}

Recebimento: 20 fev. 2017

Aceitação: 29 abr. 2017

\begin{abstract}
Como citar este artigo / How to cite this article (informe a data atual de acesso / inform the current date of access):
\end{abstract}
VALENCIA-TELLO, Diana Carolina. Las emociones en el proceso de paz colombiano. Revista da Faculdade de Direito UFPR, Curitiba, PR, Brasil, v. 62, n. 1, jan./abr. 2017, p. 231 - 254. ISSN 2236-7284. Disponível em: $<$ http://revistas.ufpr.br/direito/article/view/50782>. Acesso $\quad$ em: $30 \quad$ abr. $2017 . \quad$ DOI: http://dx.doi.org/10.5380/rfdufpr.v62i1.50782.

\section{RESUMEN}

El conflicto armado colombiano es el conflicto más prolongado de América. En septiembre de 2016 se firmó el primer Acuerdo de Paz entre el Gobierno de Juan Manuel Santos y las Fuerzas Armadas Revolucionarias de Colombia (FARC). Con la finalidad de refrendar el Acuerdo de Paz por todos los colombianos, el presidente Santos convocó un Plebiscito el pasado 02 de octubre de 2016. El acuerdo no fue avalado por el 50,22\% de los colombianos, pero el gran ganador de la jornada fue la abstención que alcanzó el 62\%. En la actualidad, no existe consenso sobre las causas del conflicto armado, ni tampoco sobre los posibles caminos para la paz, razón por la cual el país está dividido sobre las posibilidades del dialogo. La falta de consensos alrededor del proceso de paz, unido al desconocimiento y a la incertidumbre que provocaron los diálogos con las FARC, generó que la discusión política se caracterizara por falta de argumentos o explicaciones claras sobre los puntos a favor y en contra del proceso, lo que fue evidente en las pasadas elecciones presidenciales de 2014 y en el plebiscito por la paz, en donde las campañas se concentraron más en los sentimientos de esperanza y miedo que genera el tema de la paz, sin realizar mayores discusiones sobre los principales temas del proceso. En medio de campañas políticas que priorizan las emociones antes que los argumentos racionales, ¿Cómo podemos construir caminos de paz que ayuden a la reconciliación entre los diversos actores del conflicto?

PALABRAS CLAVE

Campañas políticas. Cognición política. Emociones. Proceso de paz. Colombia.

\begin{abstract}
The Colombian armed conflict is the longest conflict in America. In September 2016, the first Peace Agreement between the Government of Juan Manuel Santos and the Revolutionary Armed Forces of Colombia (FARC) was signed. In order to endorse the Peace Agreement by all Colombians, president Santos called a Plebiscite last October 2016. The agreement was not endorsed by $50.22 \%$ of Colombians, but the great winner of the day was abstention that reached $62 \%$. At present, there is no consensus on the causes of the armed conflict, nor on the possible paths to peace, which is why the country is divided on the possibilities of dialogue. The lack of consensus around the peace process, led to a poor political discussion, characterized by lack of clear arguments or explanations about the
\end{abstract}


good and bad points of the peace agreement. The last political campaigns were focused more on the feelings of hope and fear generated by the peace process, without further discussions on the main issues of the process. In the midst of political campaigns that prioritize emotions rather than rational arguments, how can we build paths of peace that help reconciliation between the various actors in the conflict?

\section{KEYWORDS}

Political campaigns. Political cognition. Emotions. Peace process. Colombia.

\section{INTRODUCCIÓN}

Según el informe ¡Basta ya! Colombia: Memorias de guerra y dignidad, elaborado por el Centro Nacional de Memoria Histórica (2013, p. 19), el conflicto armado colombiano se ha prolongado por más de 50 años y, en razón a su magnitud, ferocidad y degradación, es difícil explicar la guerra. Este informe calcula que entre 1958 y 2012 el conflicto armado ha ocasionado la muerte de por lo menos 220.000 personas. Otros datos presentados en el informe confirman que ha dejado aproximadamente 6,9 millones de desplazados; 45.000 personas desaparecidas y, 27.000 personas secuestradas.

Con la finalidad de terminar el conflicto armado, el 26 de septiembre de 2016 se firmó oficialmente en Cartagena de Indias, el primer Acuerdo de Paz entre el Gobierno de Juan Manuel Santos y las Fuerzas Armadas Revolucionarias de Colombia (FARC), tras cuatro años de conversaciones en La Habana, Cuba.

El Acuerdo de Paz de 297 hojas se hizo público el pasado 24 de agosto; es decir, casi un mes antes de la firma oficial del Acuerdo y, en consecuencia, la opinión pública tuvo solo un mes para conocer el contenido final del Acuerdo; pues las negociaciones se realizaron a puerta cerrada la mayor parte del tiempo.

Con la finalidad de refrendar el Acuerdo de Paz por todos los colombianos, el presidente Santos convocó un Plebiscito el pasado 02 de octubre. El acuerdo no fue avalado por el 50,21\%, pero fue avalado por el 49,78\% de los votantes, lo que representa una diferencia menor del 0,5 porcentual entre los colombianos a favor y en contra del Acuerdo Final con las FARC. Aún así, se debe resaltar que el gran ganador de la jornada fue la abstención que alcanzó el 62\% (Registraduría Nacional del Estado Civil, 2016).

El resultado del Plebiscito por la Paz sorprendió no sólo al gobierno, sino también a los integrantes de la campaña por el No. El 05 de octubre, en el Diario La República (2016) el Gerente de la Campaña por el No, Juan Carlos Vélez, declaraba que: “el No fue la campaña más barata y 
efectiva en mucho tiempo. Su costo-beneficio es muy alto.” En su opinión, la estrategia de buscar que la "gente saliera a votar verraca” funcionó. El dirigente explicó la campaña en los siguientes términos:

Unos estrategas de Panamá y Brasil nos dijeron que la estrategia era dejar de explicar los acuerdos para centrar el mensaje en la indignación. En emisoras de estratos medios y altos nos basamos en la no impunidad, la elegibilidad y la reforma tributaria, mientras en las emisoras de estratos bajos nos enfocamos en subsidios. En cuanto al segmento en cada región utilizamos sus respectivos acentos. En la Costa individualizamos el mensaje de que nos íbamos a convertir en Venezuela. Y aquí el No ganó sin pagar un peso. En ocho municipios del Cauca pasamos propaganda por radio la noche del sábado centrada en víctimas. (LA REPÚBLICA, 2016)

La campaña por el No al plebiscito por la paz es un ejemplo de cómo las campañas políticas utilizan de forma exagerada emociones como la esperanza y el miedo, sin que exista una reflexión responsable sobre las consecuencias que puede tener éste tipo de estrategias para la cohesión social y la estabilidad del país. Como bien lo explica Narváez:

Los sagaces de la política saben bien que explorar las rabias, los rencores y los deseos de venganza de los electores es "una economía política” de jugosos réditos electorales. Que lejos está esto de la definición que Plutarco ofreció de la política como aquello que sustrae al odio su carácter eterno. El caso de Colombia en la coyuntura actual refleja claramente esta tendencia: bajo el reclamo dogmático de un maximalismo jurídico (que nada quede impune) se esconde el enarbolamiento de la rabia y la venganza. Economía del odio que Savater denomina "Los recuerdos envenenados", que David Rieff cuestiona en su libro "Contra la Memoria” y Svetlan Teodorov llama "Los abusos de la memoria". Los tres autores afirman la importancia y urgencia de hacer re-composición de la memoria. (NARVÁEZ, 2013)

En este orden de ideas, el presente artículo busca analizar cómo el exagerado apelo a emociones envenenadas en la política colombiana no ha permitido, hasta el momento, la construcción de caminos de paz que ayuden a la reconciliación entre los diversos actores del conflicto. Consideramos que después de décadas de guerra y sufrimiento es fundamental despertar otro tipo de emociones como la bondad, la compasión y el perdón, para canalizar los compromisos de inclusión, igualdad o mitigación del sufrimiento, que deben existir en la sociedad para la construcción de una paz estable y duradera.

Según Martha Nussbaum, las emociones públicas tienen grandes consecuencias en el progreso de una nación, pues éstas pueden impulsar la lucha por el logro de objetivos, pero también pueden descarrilar la lucha, introduciendo o reforzando divisiones y jerarquías presentes en las sociedades. Por ello afirma que: “[...] toda sociedad necesita reflexionar sobre la estabilidad de su cultura política a lo largo del tiempo y sobre la seguridad de sus valores más preciados por ella en épocas de tensión.” (NUSSBAUM, 2017, p. 15)

Así, buscando realizar una reflexión sobre el tipo de emociones utilizadas para impulsar el proceso de paz colombiano, una versión preliminar de este artículo fue presentado en el XXVII World 
Congress of the International Association for the Philosophy of Law and Social Philosophy realizado en Washington D.C. en 2015, el cual estuvo dedicado al análisis del “Derecho, las Razones y las Emociones”. Varias ideas aquí presentadas se encuentran en una fase inicial de investigación, utilizando principalmente el marco conceptual elaborado por Manuel Castells en su libro Comunicación y Poder (2011).

En el presente artículo, primero se analizará de forma general el papel de las emociones en los procesos de comunicación, para después estudiar la forma como se realizan las campañas políticas en la actualidad con las nuevas tecnologías. En la tercera sección, estudiaremos algunos antecedentes sobre el proceso de paz colombiano, para después en la cuarta sección tratar el papel de las emociones en las campañas políticas y el proceso de paz colombiano. Finalmente se realizarán algunas conclusiones.

\section{EL PAPEL DE LAS EMOCIONES EN LOS PROCESOS DE COMUNICACIÓN}

Los humanos desde que nacemos necesitamos de la protección (por varios años) de otros seres humanos, para sobrevivir y aprender diversas habilidades cognitivas y emocionales necesarias para socializar y comunicarnos de forma efectiva con nuestros pares. Por esto, Aristóteles (1998) categóricamente afirmaba que la propia naturaleza humana arrastra instintivamente a todos los hombres a la asociación política, porque el hombre es “un ser naturalmente sociable”.

La comunicación como habilidad social que permite relacionarme con el otro y manifestar al mundo mis ideas y sentimientos, es fundamental en la construcción de nuestras relaciones sociales, y por ende, en la construcción de nuestras instituciones; porque es a través de la comunicación que establecemos significados y propósitos compartidos que nos ayudan a determinar las reglas básicas que gobiernan nuestras relaciones y las instituciones en la sociedad. En este orden de ideas, la comunicación de ideas y sentimientos es clave en todo proceso de lucha por el poder, porque es mediante la comunicación que construimos significados entre los miembros de la comunidad ayudando a fortalecer la legitimidad de nuestras instituciones; lo que se traduce en comportamientos más colaborativos o cooperativos entre los miembros. Pero, también es mediante la comunicación que cuestionamos las instituciones existentes, creando resistencias sobre el orden previamente establecido; lo que se refleja en comportamientos menos colaborativos con relación a los objetivos comunes planteados por las instituciones que representan la colectividad. Esto lleva a Castells (2011, p. 34) a afirmar que: 
La capacidad para lograr el consentimiento o al menos para instar el miedo y resignación respecto al orden existente es fundamental para imponer las reglas que gobiernan las instituciones y las organizaciones de la sociedad. $\mathrm{Y}$ en todas las sociedades esas reglas representan las relaciones de poder incorporadas en las instituciones como resultado de los procesos de lucha y compromiso entre actores sociales enfrentados que se movilizan por sus intereses bajo la bandera de sus valores.

Así, la dominación (entendida como poder que reside en las instituciones sociales) sobre los otros se realiza mediante procesos de comunicación que pueden lograr consentimiento o instar el miedo en los individuos pertenecientes a una determinada sociedad, buscando establecer un determinado orden, con relaciones de poder definidas entre quienes tienen derecho a mandar y quienes tienen el deber de obedecer.

Por lo tanto, el poder y la contestación al poder se ejercen con ayuda de argumentos y sentimientos compartidos en las sociedades, creando diversas tensiones que dan forma a las instituciones, los valores y las creencias en los individuos, los cuales varían permanentemente a través del tiempo.

Para Belloso Martin (2017) los productos de la historia son construcciones que tienen fecha de caducidad pues los problemas del pasado que requieren explicación cambian en cada presente; porque las teorías, los métodos y las técnicas cambian, de forma tal que cada generación tiene que rehacer la historia toda. En este sentido, existe una sinapsis entre las razones y las emociones que son utilizadas para construir el presente, el pasado y el futuro.

La sinapsis existente entre la razón y la emoción al momento de construir las diversas relaciones de poder en las sociedades está bien documentada por diversos autores. Según Cruz Castillo (2012), la visión tradicional racionalista colocaba a las emociones por fuera del campo de la razón, pero nuevos estudios han demostrado que las emociones forman parte del ejercicio de la racionalidad, pues tienen una inferencia directa en la toma de decisiones, tanto desde los marcos interpretativos culturales, como desde los elementos objetivos que están contenidos en la acción social y política.

Damasio en su libro El error de Descartes (1996, p. 274) demuestra como es un error colocar a la razón y los sentimientos en lados opuestos; ya que los sentimientos tienen un marcado predominio en las labores de la razón y, en su concepto, “[...] tomar conciencia del rol preponderante de los sentimientos nos da la oportunidad de realzar sus efectos positivos y disminuir al mismo tiempo su potencialidad lesiva”. En concreto Damasio afirma:

Sólo sugiero que determinados aspectos del proceso de la emoción y del sentimiento son indispensables para la racionalidad. En su versión afirmativa, los sentimientos nos encaminan en la dirección adecuada, nos llevan al lugar apropiado en un espacio decisorio en que podemos poner en acción, convenientemente, los instrumentos de la lógica. Enfrentamos la 
incertidumbre cada vez que tenemos que hacer un juicio moral, decidir el curso de una relación personal, elegir medios que impidan la miseria en la ancianidad, planear la vida que tenemos por delante. Emociones y sentimientos, junto con la encubierta maquinaria fisiológica subyacente, nos asisten en la amedrentadora tarea de predecir el futuro incierto y planear consecuentemente nuestros actos. (DAMASIO, 1996, p. 12-13)

Por su parte, Jasper (1998, p. 404) afirma que las emociones son parte de la cultura y por ello los seres humanos somos socializados o no socializados bajo determinados sentimientos y emociones; de forma tal que las emociones son fundamentales en las acciones y relaciones sociales pues moldean las expectativas sociales (lo deseable y lo no deseable). Así, las emociones son inseparables de los procesos políticos, ya que son un componente esencial del proceso interpretativo que crea el mundo de cada persona dentro de su comunidad política. En este sentido, Gould (2004, p. 45) afirma que: “en lugar de ser un impedimento para el pensamiento, sentir es uno de los muchos modos en que las personas adquieren conocimiento y comprensión.”

Según Nussbaum (2017, p. 14-15), todas las sociedades están llenas de emociones y las democracias liberales no son la excepción. Muchas emociones públicas tienen que ver con los objetivos de la nación, las instituciones y sus dirigentes; pero también tienen que ver con la geografía, con los principios y compromisos clave que marcaron la historia de las comunidades, así como la percepción que los ciudadanos comparten sobre un espacio público en común.

Para Castells (2011, p. 35), luego de analizar a Foucault (1975), Weber (1978) y Habermas (1976), determina que existe un apoyo complementario y recíproco entre los dos principales mecanismos de formación de poder, que son: la violencia y el discurso. Ambos utilizan las emociones de diversas formas. La violencia, o la amenaza de violencia, (como forma de coacción física) es la forma más antigua y básica de poder, que todos los pueblos han usado en algún momento para instaurar un determinado orden, con base en el miedo a las autoridades y las instituciones establecidas. Por su parte, los discursos (como técnica para lograr el consentimiento de otros ciudadanos sin recurrir al uso de la fuerza) utiliza la comunicación de razones y emociones entre los miembros de la comunidad para convencer a la mayoría, buscando el consentimiento y la legitimidad en las decisiones que afectan a todos.

Para Cruz Castillo (2012), las emociones son fundamentales al momento de involucrar los individuos en la acción política, pues los diversos procesos sociales moldean las emociones causando que estas creen y/o refuercen el universo político a través del proceso de la participación donde se desarrollar la interacción social. De esta forma, "la realidad no podría explicarse en su totalidad si no se incorpora al actor sentiente en las dinámicas humanas de interactividad e intercomunicación.” 
Teniendo en cuenta lo anterior, la retórica, entendida como el arte de la persuasión, y como un arte político, se caracteriza por el uso de diversas técnicas para enfrentar ideas, opiniones y argumentos que buscaban convencer al auditorio sin necesitar de la coacción física o del uso de la violencia.

En la antigua Grecia, los sofistas (termino que inicialmente significaba sabio) fueron los primeros que se interesaron por el debate entre ideas opuestas. El juego de los opuestos señalaba que cada hombre en sus relaciones sociales es apenas una parte del todo y, que para ser entendido, debía ser pensado en relación a su opuesto. En el derecho, el juego de los opuestos ayudó a determinar que para que exista justicia es necesario escuchar a la contraparte. En la política, el juego de los opuestos permitió que en las asambleas de ciudadanos se discutieran las ideas antes de llegar al consenso político. El debate de ideas implicaba desde el inicio la existencia de diversos intereses, y, a veces, una ruptura en la comunidad política, ya que la opinión de un grupo de ciudadanos podía ser diametralmente opuesta a la opinión de otro grupo de ciudadanos. Así, la política existe cuando hay dos o más intereses/ideas en discusión, ya que todo debate político necesita de argumentos y contra argumentos (CIRNE-LIMA, 2002, p. 33-35).

Para Protágoras, uno de los principales representante de los sofistas, las creencias son relativas y subjetivas, porque todo depende del punto de vista de cada persona y, por lo tanto, son imposibles las definiciones absolutas, pues lo que puede ser verdadero para una persona, puede ser falso para otra (BUCKINGHAM et al., 2011). Para los sofistas, todo argumento tiene dos polos que pueden ser válidos, lo que causó el uso indiscriminado de argumentos con el fin de ganar debates sin mayores referentes éticos o morales, generando el desprecio histórico por los sofistas por defender cualquier argumento como verdad a cambio de dinero (CIRNE-LIMA, 2002, p. 33-35).

Teniendo en cuenta la importancia de los debates para el funcionamiento de la democracia, Aristóteles en su libro sobre Retórica, determinó que en todo discurso existen dos elementos principales que se coordinan para convencer. El primero son los argumentos o las razones lógicas que el orador presenta y, el segundo, no menos importante, son las emociones que el orador debe transmitir para que el público sienta empatía hacia él y hacia las ideas por él presentadas. Aunque las emociones pueden no tener relación alguna con los argumentos lógicos presentados, son fundamentales a la hora de convencer al público (VALE DOS SANTOS, 2014, p. 86). En palabras de Aristóteles (2005, p. 159), las emociones:

[...] son las causas que hacen alterar los seres humanos e introducen cambios en sus juicios, en la medida en que ellas comportan dolor y placer: tales son la ira, la compasión, el miedo y otras semejantes, así como sus contrarias. (traducción nuestra) 
Para persuadir al público el orador debe mostrarse confiable, pues el público se sentirá inclinado a transferir el contenido del discurso a la credibilidad del orador, especialmente en los casos en que existe desconocimiento sobre el asunto tratado. Según Aristóteles (2005, p. 160) para que el orador tenga credibilidad ante el público es necesario que demuestre prudencia, virtud y benevolencia, de tal forma que cuando los oradores recurren a la mentira es por falta de alguna de ellas o, por la falta de todas.

Así, las emociones presentadas por el orador son fundamentales a la hora de persuadir al público pues los sentimientos despertados mueven a las personas en dirección a un determinado juicio o altera la severidad del mismo. El orador debe procurar que los oyentes experimenten algún tipo de sentimiento que sea favorable al contenido del discurso por él presentado, para inducir los juicios de los oyentes en dirección a lo que es conveniente. Aún así, para que el discurso sea legitimo se deben presentar argumentos que respeten las leyes de la lógica, pero, al mismo tiempo, se deben utilizar las emociones para mover a las multitudes, sin llegar a trasformar el discurso en manipulación (VALE DOS SANTOS, 2014, p. 90).

Aristóteles en la Retórica (2005) caracteriza trece emociones, que son: ira, calma, amistad, enemistad, temor, confianza, vergüenza, desvergüenza, amabilidad, piedad, indignación, envidia y emulación. Aquí debemos resaltar el uso del juego de los opuestos, para describir las emociones que pueden ser utilizadas en un discurso.

Con esto, podemos inducir que la democracia en la Antigua Grecia implicaba un proceso de permanente discusión y debate entre ciudadanos libres, quienes podían presentar sus ideas y sentimientos ante otros ciudadanos; quienes, a su vez, debían ser convencidos mediante diferentes técnicas de persuasión, que incluían argumentos lógicos y apelo a las emociones en favor de determinadas ideas y valores latentes en la comunidad política. En la actualidad la forma de hacer política se ha modificado totalmente en razón al surgimiento de las sociedades en masa y las nuevas tecnologías como veremos a continuación.

\section{CAMPAÑAS POLÍTICAS Y NUEVAS TECNOLOGÍAS}

Para Alonso y Adell (2011, p. 69-70) el comportamiento político en los últimos tiempos ha cambiado notablemente en razón a la creciente importancia de las telecomunicaciones y al comportamiento menos predecible y mucho más consumista de los ciudadanos.

Castells (2008, p. 352) citando a Fallows (1996) evidencia como la tecnología ha transformado la política por la capacidad de vincular el sistema de los medios en tiempo real con el 
marketing político. Esto porque desde finales de la década de 1970, la introducción de los ordenadores en la tabulación de las encuestas, posibilitó la realización de “investigaciones estratégicas” que permitieron analizar grupos seleccionados de potenciales votantes para modificar las estrategias e, inclusive, el contenido de los mensajes en la medida en que se desarrollaba la campaña política.

Cuando la diversificación y la descentralización de los medios de comunicación fue posible en la década de 1970, debido a las nuevas tecnologías, el dominio de los medios en las actitudes y las conductas políticas de la población se hizo más amplio (GARBER, 1996; HACKER, 1996 apud CASTELLS, 2008, p. 353). La televisión a cable y las tertulias radiofónicas ayudaron a personalizar la audiencia y permitieron a los políticos orientar mejor su mensaje, según los diferentes grupos de interés. Los sectores ideológicos tuvieron una mayor oportunidad para presentar sus argumentos sin el filtro de los medios mayoritarios. En este contexto, la aparición del internet permitió también ampliar la propaganda de las campañas, los foros de debate y la conexión de los militantes (KLINENBERG; PERRIN, 1996 apud CASTELLS, 2008, p. 353). Las nuevas tecnologías permiten que los medios de comunicación se dirijan a audiencias específicas, interesadas en confirmar sus opiniones más que informarse en otras fuentes sobre las opiniones opuestas a las propias (CASTELLS, 2011, p. 263-264).

Por lo tanto, la lógica de los medios promueve que ellos deban trabajar para aumentar las audiencias específicas y competir por el entretenimiento, al mismo tiempo que deben buscar independencia ante la política para inducir credibilidad. Esta lógica causa que las noticias estén más interesadas en el espectáculo político, que en la noticia que explica e informa a la opinión pública, buscando opiniones responsables sobre los temas de interés público (GITLIN, 1980, p. 28 apud CASTELLS, 2008, p. 354).

En la actualidad, los políticos y los gobiernos se volvieron dependientes de las evaluaciones diarias del impacto político de sus decisiones sobre la opinión pública, la cual es medida por encuestas y por estudios de análisis de imagen realizados por expertos contratados, mediante diversas técnicas de marketing político, usando las nuevas tecnologías disponibles (VALENCIA TELLO, 2015, p. 186) Esto a pesar del margen de error que pueden tener las encuestas, las cuales en muchas oportunidades se han mostrado poco efectivas a la hora de predecir las elecciones de la ciudadanía.

En Marketing Político 2.0, se afirma que la mayoría de los candidatos en todo el mundo (en elecciones locales, municipales, sindicales, nacionales o internacionales), han comenzado a utilizar casi todas las técnicas de marketing político, como los sondeos de opinión vía encuestas, focus groups, anuncios de televisión, campañas de imagen en los medios, telemarketing, marketing directo y, cada vez más internet en todas sus formas; esto es: marketing móvil, redes sociales, etc. Con 
relación a la aparición del consumidor político, los autores analizan los efectos que ha tenido el consumismo sobre la política, señalando que los votantes “[...] quieren un producto más tangible que retórico” pues los nuevos votantes prefieren “[...] la eficiencia pragmática a los principios morales”. Así, la lucha por el poder obliga a que los candidatos deban perfilar los mensajes de manera más efectiva; es decir, deben utilizar técnicas de comercialización y venta que funcionan en el mundo empresarial; aunque estas técnicas deben ser adecuadas al universo infinitamente más complejo de la política, donde: “[...] no se juega sólo con dinero sino con lo más preciado que puede tener una persona: sus esperanzas.” (ALONSO; ADELL, 2011, p. 72).

En estos términos, Alonso y Adell (2011, p. 72) presentan el marketing político como la solución para una clase política que necesita romper el desencanto y conseguir que la gente (previamente identificada) se movilice y vaya a votar. En su concepto, un marketing adecuado permite: “[...] reavivar el fuego del activismo” usando las segmentaciones adecuadas, diseñando los mensajes en función de las encuestas y focus group, los cuales requieren ser galvanizados por medio de técnicas publicitarias y de comunicación profesionales, además del uso de las redes sociales que ayudan a "sentir" la proximidad del candidato a los votantes.

En este contexto, los medios de comunicación se han convertido en un campo de batalla donde las fuerzas y las personalidades políticas y los grupos de presión están en permanente competencia, tratando de debilitar a los oponentes, para obtener mayores beneficios en las encuestas, votaciones y decisiones del gobierno. Por esta razón, la política en los medios de comunicación es por definición contradictoria, pues actúan diversos actores y diversas estrategias políticas, generando consecuencias inesperadas que nadie puede controlar (CASTELLS, 2008, p. 346-349). La idea de diseñar los mensajes en función de las encuestas y focus group, evidencia que este tipo de política informacional no se importa con la cohesión social o, con la idea de comunidad política y espacios de convivencia pacífica y respetuosa de los diversos grupos existentes en la sociedad.

El marketing político es plenamente consciente de las diferencias existentes entre la venta de productos comerciales y “productos políticos”. Alonso Coto y Adell (2011, p. 74) señalan que el mercado político es mucho más complejo, puesto que hay demandas más complicadas y conflictivas. Además, el producto político es intangible y mucho más difícil de comprender y de crear; debido a que los productos tienen un valor simbólico y sólo hay un rango disponible, lo que causa que el consumidor sólo apoye un producto mientras rechaza todos los demás. También se afirma que el mercado político muchas veces no sabe lo que quiere y, que la política tiene que ver con ideologías, no sólo con gustos y disgustos sobre las marcas. En definitiva, “[...] la política es una actividad de mucho más largo plazo que el mero marketing empresarial”. 
De esta forma la política en la actualidad parece no estar interesada en llegar a consensos para establecer estrategias sobre los principales problemas de las sociedades, pues la "eficiencia pragmática” no tiene tiempo para debatir sobre los valores, principios y compromisos clave que deberían existir, sino por el contrario, el interés principal se encuentra en luchar por el poder para llegar al Estado, a veces a cualquier precio.

Así, el aumento de la comunicación con ayuda de las nuevas tecnologías no implica el aumento de las capacidades de los políticos y de los ciudadanos para realizar debates responsables y llegar a consensos que beneficien a toda la comunidad. Por el contrario, la información muchas veces es contradictoria y beligerante ampliando de diversas formas la fragmentación de nuestras sociedades e impidiendo obtener acuerdos mínimos sobre las políticas que afectan a toda la comunidad.

La política en los medios de comunicación tiene poco que ver con la idea de democracia deliberativa basada en la exposición de argumentos profundos, debates y discusiones civilizadas. Los medios pocas veces se concentran en el análisis de los argumentos. Por el contrario, se interesan más por los detalles del espectáculo político, tales como quien gana, quien pierde, cómo, porqué y cuál fue la última jugada política; lo que demuestra que éste tipo de política se concentra mucho más en las emociones públicas, sin mayor conexión con los argumentos racionales que también deberían ser discutidos.

En este contexto, las campañas políticas muchas veces terminan deslegitimando la propia democracia. La falta de debates serios en los medios de comunicación sobre los principales problemas en nuestras sociedades, evidencian el excesivo apelo a las emociones públicas, lo que termina siendo insuficiente para generar consensos y/o políticas públicas coherentes sobre los principales temas de interés público.

De otro lado, los altos costos que deben ser asumidos para entrar en la competencia política por el poder en el Estado, obligan a que todo candidato a un cargo de representación popular deba disponer de importantes recursos económicos, comprometiendo así la defensa del interés general a favor de los patrocinadores.

En este sentido, el apoyo de grupos económicos a las campañas mediante el financiamiento, crea profundos cuestionamientos sobre la legitimidad del candidato o del partido, debido a que difícilmente se puede representar a la mayoría cuando los candidatos son financiados por grupos económicos. Esto sin contar los casos en que se comprueba la existencia de financiamientos ilegales en las campañas.

El espectáculo político cada vez puede ser más agresivo, ocasionando fuerte polarización de las campañas y de la sociedad, sin mayores posibilidades de llegar a acuerdos mínimos que permitan 
la existencia de una democracia sana que fortalezca la legitimidad del Estado y de sus instituciones. Un ejemplo de fuerte polarización de las campañas políticas fue la campaña del proceso de paz colombiano, pero para comprender lo sucedido, primero debemos analizar algunos antecedentes.

\section{ANTECEDENTES DEL PROCESO DE PAZ COLOMBIANO}

En Colombia, el conflicto armado ha sido una constante a lo largo de su historia. A finales de la década de los años ochenta existía cierto consenso en torno a que las guerrillas tenían motivos políticos para revelarse en contra del Estado, razón por la cual para lograr la paz era justo promover un cambio político y social en las instituciones y en las políticas públicas, lo que motivó el clamor por una Constituyente que ayudara a sentar las bases de un nuevo pacto por paz, que reconociera los intereses y las necesidades de los grupos históricamente excluidos (LEMAITRE RIPOLL, 2011, p. 4-6).

Según Lemaitre Ripoll (2011, p. 4-6) este consenso se dio en parte porque muchos estudios académicos, libros, artículos de opinión y reportajes relacionaban la violencia de los años ochenta, con la violencia de los años cincuenta, la cual se caracterizó por tener motivaciones políticas, en razón a las desigualdades existentes en amplios sectores de la población y a la consecuente exclusión por parte del Estado de grupos con interés de participar del debate público. Así, no sorprende que la solución al conflicto armado en Colombia se concentrara en la inclusión de grupos de izquierda en el debate político y en la mejora de las condiciones sociales y económicas de los grupos históricamente excluidos de la sociedad colombiana.

La nueva Constitución de 1991 representaba ese anhelo de paz de los colombianos, quienes mediante el consenso sobre importantes reformas institucionales, buscaban crear un Estado más democrático, participativo y respetuoso de los derechos humanos en todos los sectores de la sociedad, para así construir las condiciones materiales que hicieran posible la anhelada paz en Colombia.

Sin embargo, a pesar de todos los esfuerzos realizados, hasta el momento no ha sido posible concretizar la paz. Los reiterados fracasos para lograr la paz han generado incredulidad y escepticismo en muchos colombianos, que ya no creen en la posibilidad de alcanzar la paz mediante el diálogo político; lo que provoca que la única solución posible y justa sea la guerra contra los grupos ilegales, con todas las consecuencias que ello implica.

En este contexto de incredulidad hacia la paz, en las pasadas elecciones presidenciales de 2014 el tema central de debate fue precisamente el proceso de paz entre el Gobierno del Presidente Santos y las FARC en la Habana. En esta ocasión no existía consenso sobre las causas del conflicto 
armado, ni tampoco sobre los parámetros de justicia que deberían ser utilizados o los posibles caminos para la paz, razón por la cual el país estaba dividido sobre las posibilidades del dialogo. Para muchos observadores externos era insólito verificar como un país que lleva medio siglo de guerra sigue todavía dividido casi por mitades en torno a si es posible una solución negociada al conflicto.

La falta de consenso entorno a la paz se genera no sólo por la experiencia compartida de varios procesos de paz fracasados, sino también, por la falta de confianza sobre la negociación (que se realizó la mayor parte del tiempo a puerta cerrada) y la desconfianza histórica hacia las FARC. Aun así, para muchos colombianos, medio siglo de lucha armada demuestra que el camino de las armas no tiene vencedores sino sólo perdedores, por tanto, el dialogo político es la mejor salida al conflicto armado, pero, todavía no son claros los límites que debería tener el dialogo político, ni los parámetros de justicia que debería ser aplicados para que el proceso de paz sea considerado legítimo y constructor de paz, en una sociedad fuertemente afectada por varios años de conflicto armado.

En cualquier caso, como bien lo afirma Belloso Martin (2017) "La memoria vengativa dificulta el tránsito a la democracia. El componente de transformación de la memoria, para que se abra a la reconciliación y al olvido, es, probablemente, la tarea más dificultuosa.” Narváez (2017) analizando el informe de Memoria Histórica de 2013, llama la atención de cómo Colombia se muestra como: una sociedad fracturada y lo peor, infectada con el virus persistente de "memorias sin futuro que toman la forma extrema de la venganza, la cual a fuerza de repetirse niega su posible superación [...] En efecto, la venganza parte de la negación de la controversia y de la posibilidad de coexistir con el adversario... Es la negación radical de la democracia”.

La falta de consensos alrededor del proceso de paz, unido al desconocimiento y a la incertidumbre sobre los cambios que deberían realizarse en el ordenamiento jurídico, genera que la discusión política se caracterice por falta de argumentos o explicaciones claras sobre los puntos a favor y en contra del proceso, lo que fue evidente en las pasadas elecciones presidenciales de $2014 \mathrm{y}$, en la campaña por el Si y por el No en el Plebiscito por la paz; en donde las campañas se concentraron en los sentimientos de esperanza y miedo que genera el conflicto armado, sin realizar mayores discusiones sobre los principales temas del proceso.

Así, las pasadas elecciones presidenciales de 2014 fueron un ejemplo de fuerte polarización entre las dos grandes campañas (Santos - Zuluaga) en niveles nunca antes vistos. Según Álvaro Sierra Editor Jefe de la Revista Semana (2014), las campañas pasaron “[...] de la plaza pública a los estrados judiciales, con hackers, narcos y asesores asumiendo el protagonismo que deberían tener los argumentos políticos”. 
La polarización de las elecciones presidenciales en Colombia causó que los ciudadanos tuvieran que decidir por dos proyectos totalmente opuestos sin ninguna posibilidad de consenso entre los grupos mayoritarios, esto fue, o seguir con el proceso de paz con las FARC en Cuba votando por Santos o, continuar la guerra, apostando a la derrota militar de las FARC votando por Zuluaga. Sobre la falta de argumentos y consenso en las pasadas elecciones presidenciales, Sierra (2014) afirmó:

Toda una paradoja. El llamado proceso de paz -las negociaciones entre el Gobierno y las FARC en La Habana para poner fin al conflicto armado- despierta escaso entusiasmo entre la gente. Se encuentra en un puesto muy bajo entre las prioridades que la opinión pública expresa en las encuestas. Y una amplia mayoría de los colombianos se dice escéptica o pesimista sobre su resultado. Sin embargo, la paz se ha posicionado una vez más en la historia de las elecciones presidenciales como el tema central en el debate.

Un debate simplista, de escasos argumentos y no poca manipulación. El presidente Juan Manuel Santos ha buscado su reelección presentándose como el candidato de la paz, con palomitas de colores en su publicidad y con una palomita como prendedor en su saco en los debates que cerraron la campaña, los únicos a los cuales él asistió. Sin embargo, ha sido escasa la pedagogía que él y su gobierno han hecho para convencer a los colombianos de la necesidad del proceso, de la conveniencia de negociar con la guerrilla, de por qué esta es un interlocutor legítimo. Y si el público en las grandes ciudades no se siente ‘tocado’ por lo que pasa en La Habana, en el resto del país, en las regiones, lo que ocurre en la isla parece abstracto y lejano.

Del otro lado, en el uribismo, el expresidente Álvaro Uribe, su candidato Óscar Iván Zuluaga y sus seguidores truenan contra una suerte de conspiración entre Santos y las FARC y enarbolan argumentos como que se negocia a espaldas del país y otras críticas que, en lugar de apuntar a una discusión racional, buscan apalancarse en los sentimientos de prevención, desconfianza y aborrecimiento que la mayoría de los colombianos experimentan ante la guerrilla. El candidato del uribismo, Óscar Iván Zuluaga, ha pasado de anunciar que romperá el proceso de negociaciones a anunciar que pondrá a las FARC condiciones tales que harían improbable que continúe. El expresidente ha llegado a hablar de "oligarquía comunistoide”, como dijo en uno de sus rotundos trinos. Y sus acusaciones de que bajo este gobierno ha tenido lugar un deterioro en la seguridad es un argumento que ha calado en muchas zonas del país.

Las contradictorias posiciones de los candidatos presidenciales que pasaron a segunda vuelta son un claro ejemplo de la polarización del país, sin que exista un debate profundo sobre los argumentos a favor y en contra del proceso de paz con las FARC. Narváez (2013) al analizar los procesos de transición en Chile y en Sudáfrica, identifica que hubo más justicia-verdad y menos justicia-castigo. Concluye que los procesos pacíficos sostenibles de transición, exigen liderazgos carismáticos que apliquen la cultura del perdón y la reconciliación; permitiendo con esto superar las lógicas enfrentadas del maximalismo moral que reclama la aplicación de justicia en todo su rigor, sin importarle que se prolonguen periodos de justicia sin democracia y, por otra parte la lógica del minimalismo pragmático que reclama la consolidación de la democracia sin justicia. Por el momento Colombia no cuenta con liderazgos carismáticos que permitan la cultura del perdón y la reconciliación. 
En consecuencia, el resultado del Plebiscito por la paz del 2 de octubre es absolutamente coherente con la polarización registrada en las pasadas elecciones, pero para comprender por qué a los colombianos nos cuesta llegar a consensos mínimos sobre el conflicto armado, debemos entender el papel de las emociones en las campañas políticas.

\title{
4 EL PAPEL DE LAS EMOCIONES EN LAS CAMPAÑAS POLÍTICAS Y EL PROCESO DE PAZ COLOMBIANO
}

La política como practica social que permite el debate y la persuasión para convencer, se realiza a través de la comunicación de ideas y sentimientos entre individuos en colectividades especificas con el fin de llegar a acuerdos que fomenten las asociaciones y la cooperación en beneficio del conjunto de la sociedad. Por lo tanto, la política ha sido fundamental para la supervivencia de los pueblos y para el aumento del bienestar de la población, evitando el uso de la fuerza física para lograr consensos y determinar reglas de convivencia entre los individuos.

La comunicación de ideas y sentimientos determina la manera de actuar de los individuos y de las sociedades, por ello, comprender el proceso de comunicación entre individuos se torna fundamental para entender cómo se construyen y se desafían las relaciones de poder existentes en las sociedades, especialmente en las campañas políticas en donde se definen quienes serán los líderes que tendrán a cargo la gestión de los asuntos públicos en comunidades especificas por determinados periodos de tiempo. Castells (2011, p. 191-192) analiza el proceso de comunicación utilizando investigaciones neurocientíficas así:

\begin{abstract}
La comunicación se produce activando las mentes para compartir significado. La mente es un proceso de creación y manipulación de imágenes mentales (visuales o no) en el cerebro. Las ideas pueden verse como configuraciones de imágenes mentales. Con toda probabilidad las imágenes mentales se corresponden con patrones neuronales. [...] la mente es un proceso no un órgano. Es un proceso material que se produce en el cerebro al interactuar con el cuerpo propiamente dicho. Dependiendo del nivel de alerta, atención y conexión con el yo, las imágenes mentales que construyen la mente pueden ser o no conscientes.
\end{abstract}

Para Castells (2011, p. 193-195), construimos la realidad como reacción ante acontecimientos reales, internos y externos, que son procesados por el cerebro de acuerdo con modelos mentales previamente establecidos, (la mayoría de las veces de forma inconsciente) para facilitar el procesamiento de información. De esta forma, la emoción y el racionamiento se originan del mismo proceso mental mediante la conexión de millones de neuronas que permiten crear 
experiencias inmediatas o que se acumulan con el tiempo; buscando orientar a la persona en la toma de decisiones, con base en experiencias previas y/o patrones previamente establecidos ${ }^{1}$.

El cerebro percibe las emociones como sentimientos y las emociones están profundamente arraigadas en nuestro cerebro, porque han sido inducidas por el instinto de supervivencia en el largo proceso de evolución, de forma tal que las especies o individuos que no tienen un sistema de detección emocional adecuado es improbable que sobrevivan (CASTELLS, 2011, p. 195).

Cuando una persona es capaz de identificar sus sentimientos de forma consciente, estos sentimientos ayudan a controlar su comportamiento social y, por ende, influyen también en sus decisiones; vinculando sentimientos del pasado, del presente y del futuro. Esto sucede mediante la activación de las redes neuronales que asocian sentimientos y acontecimientos, lo que permite orientar al individuo hacia la toma de decisiones, conforme sus marcos mentales, que no son arbitrarios, sino que se basan en la experiencia individual y social (CASTELLS, 2011, p. 196).

Como ya fue discutido en la sección dos, cada vez existen más estudios que demuestran la integración entre cognición y emoción en la toma de decisiones políticas, resaltando que la cognición política está modelada por las emociones. De esta forma, no existe oposición entre cognición y emoción, pero es importante resaltar que existen diferentes formas de articulación entre emociones y cognición para la toma de decisiones, lo que lleva a Castells (2011, p. 202) a afirmar que:

El procesamiento de la información (cognición) puede funcionar con o sin ansiedad (emoción) generando dos formas diferentes en la toma de decisiones, una la toma de decisiones racional como proceso de información de nueva información o modelos rutinarios de decisión basados en experiencias anteriores procesadas en los mapas cerebrales.

En este orden de ideas, las emociones y las elecciones racionales son mecanismos complementarios cuya interacción en el proceso de toma de decisión depende del contexto del proceso (MARCUS et al., 2000; MACKUEN et al., 2007, p. 124-151; MARCUS, 2008 apud CASTELLS, 2011, p. 202), razón por la cual la evaluación de los acontecimientos es emocional y está determinada por los marcadores somáticos que generan los sentimientos en las personas (SPEZIO; ADOLPHS, 2007 apud CASTELLS, 2011, p. 202).

Para Huettel y Kranton (2012) comprender las bases de la cognición social ha sido una de las principales áreas de análisis de la neurociencia, la cual aplica diferentes tipos de principios metodológicos dependiendo de los diferentes sistemas mentales. En consecuencia no existe un único

\footnotetext{
1 “[...] las estructuras de los marcos no son arbitrarias. Se basan en la experiencia, y surgen de la organización social que define los roles sociales en una cultura y después queda incorporada en los circuitos cerebrales [...] Las narraciones definen los roles sociales en contextos sociales. Los roles sociales se basan en marcos que existen tanto en el cerebro como en la práctica social.” (CASTELLS, 2011, p. 197-198)
} 
prototipo en la neurociencia social, más si se tiene en cuenta las dificultades de reproducir en los laboratorios las interacciones sociales que suceden en el mundo real.

Teniendo en cuenta esta advertencia, aquí explicaremos de forma general la teoría desarrollada por Castells (2011), quien parte del supuesto que los sentimientos de alerta aumentan la importancia de la evaluación racional de la decisión a ser tomada por el individuo y, los sentimientos de calma generan mayor confianza en el individuo y menor necesidad de evaluar racionalmente las decisiones a ser tomadas. Aquí, las emociones más importantes (pero no las únicas) para el comportamiento político son el entusiasmo-depresión y el miedo-calma, las cuales se activan con base en dos sistemas emocionales diferentes. El primero (entusiasmo-depresión), referente al sistema de predisposiciones induce el entusiasmo y organiza el comportamiento para conseguir los objetivos previamente determinados. El segundo (miedo-calma), activa el sistema de vigilancia cuando se experimenta miedo o ansiedad, llevando al individuo a evaluar mejor las decisiones con base en la amenaza percibida (CASTELLS, 2011, p. 202).

Así, las emociones influyen de forma significativa en el procesamiento de información política, ya que cuando los asuntos a ser discutidos generan miedo y ansiedad, se activa el sistema de vigilancia, llevando a los individuos a evaluar mejor la información y desconfiar del status quo. Según Narváez (2017) rabia-miedo son la respuesta instintiva que los humanos manifestamos ante una amenaza, o ante una agresión. Cuando no se logra superar la rabia, el recuerdo de la ofensa puede convertirse en rencor, para luego transformarse en retaliación/venganza, momento en el que comienza a escalarse peligrosamente la violencia.

El miedo es evaluado de forma especial por Sunstein en su libro "Leyes del Miedo” (2009, p. 11-12) para explicar ¿cómo debería responder un gobierno democrático al miedo público? ¿Cuál es la conexión entre el miedo, por un lado, y la ley y la política por el otro? Ante estos interrogantes, Sunstein considera que los gobiernos que funcionan correctamente aspiran a ser democracias deliberativas y, cuando el miedo público aparece en escena se deben utilizar las instituciones para disipar el miedo cuando éste no tiene fundamento, o se debe tener capacidad de respuesta apropiada. Esto porque: “[...] las democracias deliberativas evitan la tendencia de los sistemas populistas a caer presos del miedo púbico cundo éste no tiene razón de ser y emplean salvaguardas institucionales para controlar el pánico público.”

Según Castells (2011, p. 203-204) la emoción influye en la opinión política de dos formas: o genera lealtad a los partidos, candidatos o líderes de opinión, basada en el apego a dichos lideres o, genera un examen crítico de los partidos, candidatos o líderes de opinión basado en cálculos racionales influidos por mayor ansiedad. Así, la racionalidad por sí sola nunca determina la toma de 
decisiones de los individuos y en consecuencia las emociones siempre afectaran en mayor o menor medida el procesamiento de la información política.

Bajo la lógica de la lucha por el poder a cualquier precio, cuando se requiere fortalecer la movilización política a favor de un determinado candidato, las campañas deben concentrarse en activar sentimientos de miedo y esperanza en el público para lograr mayor aprobación o rechazo conforme convenga a la campaña política.

En el caso de la campaña presidencial de 2014 del Presidente Santos el mensaje central de la campaña fue: “Con paz haremos más”. El color de la campaña fue el blanco, simbolizando la paz y de fondo se observan tres palomas, en los tres colores de la bandera de Colombia, simbolizando la unidad nacional, bajo el slogan "Unidad por la paz”.2

Evidentemente el tema central de la campaña de Santos fue la esperanza de lograr la paz con la guerrilla de las FARC en la Habana y el correspondiente miedo de continuar en guerra, en caso de no ser elegido, ya que su principal contrincante, el candidato Zuluaga, (quien paso a la segunda vuelta) había manifestado abiertamente su desacuerdo a los diálogos de la Habana. En un discurso realizado el 25 de mayo de 2014, Santos invitó a los colombianos a apoyarlo en su apuesta de paz, afirmando lo siguiente:

Ha quedado claro que en tres semanas los colombianos tendrán dos opciones: quienes queremos el fin de la guerra y los que prefieren una guerra sin fin y vamos a ganar con la paz, [...] hoy empieza la campaña de la esperanza, hoy comienza la campaña de la confianza en el futuro de nuestra patria, comienza la campaña del trabajo por la paz frente a la opción exclusiva de la guerra (EL TIEMPO, 2014).

El mensaje de esperanza de Santos ilusionó a muchos colombianos con un futuro mejor, lo que es fundamental para la construcción del proceso de paz; pero, también es cierto, que simplificar un tema tan complejo, mediante divisiones entre "quienes queremos el fin de la guerra” y quienes “prefieren una guerra sin fin” aumenta la fragmentación de la sociedad y no permite visualizar los diversos matices que existen entre posiciones contrapuestas.

La campaña electoral por la presidencia de Colombia de 2014 fue calificada como la "más sucia de su historia” por varios medios de comunicación y analistas políticos; debido a las fuertes acusaciones que permanentemente eran lanzadas por los candidatos buscando generar angustia y desconfianza en el electorado con relación al contrincante.

Entre las acusaciones principales estaba la supuesta entrada de dineros de la mafia a la campaña de Santos en 2010 y la difusión de un video donde Zuluaga aparentemente habla con un

\footnotetext{
${ }^{2}$ Un análisis más profundo sobre el tema puede encontrarse en: https://goo.gl/iQ7ojv
} 
hacker sobre operaciones de espionaje y planes de atacar el proceso de paz con la guerrilla de las FARC; acusaciones que fueron rotundamente negadas por los candidatos, no sin antes producir desconcierto y confusión entre los electores, quienes se concentraron en resaltar los bochornosos detalles del espectáculo político, dejando de lado el análisis de las propuestas presentadas por los candidatos (SALAZAR, 2014).

La forma en que se ha desarrollado la política en Colombia en los últimos años no solo es vergonzosa, sino que además genera profundos cuestionamientos sobre el Estado de derecho y la legitimidad de los candidatos (independientemente de quién gana o quién pierde) en razón a que las fronteras entre lo legal y lo ilegal, lo moral y lo inmoral se vuelven cada vez más borrosas, afectando profundamente los consensos mínimos que deberían existir para que el gobierno electo represente la mayoría de los ciudadanos.

Los intensos cuestionamientos sobre los candidatos causan que perdamos todos, pues la falta de consensos y de comunicación entre diversos sectores se rompe, generando fragmentaciones en la sociedad y la existencia de comportamientos poco cívicos y poco colaborativos en torno al Estado.

En este contexto, no sorprende que la abstención en el Plebiscito por la Paz el pasado 2 de octubre fuera del 62\%, evidenciando que el Acuerdo de Paz no logró convencer a la mayoría de la ciudadanía sobre los beneficios de finalizar el conflicto armado con las FARC. Tampoco debería sorprender que el No ganara en las urnas, teniendo en cuenta que todo raciocinio siempre se verá afectado por la emoción que despierta la situación en la persona, especialmente cuando los conflictos son complejos y no existen consensos sobre las posibles causas y soluciones que deberían considerarse en un determinado periodo de tiempo.

En nuestro concepto, el exagerado apelo a las emociones envenenadas durante todo el proceso de paz con las FARC, no ha permitido comprender de forma equilibrada y racional los principales argumentos a favor y en contra del proceso lo que es un primer obstáculo importante para lograr la reconciliación entre grupos rivales que históricamente han usado la violencia como técnica principal de dominación en razón a la imposibilidad de convencer y llegar a consensos mediante el diálogo y la cooperación. Aquí es importante resaltar el análisis que realiza Narváez (2017) así:

Los países que más recientemente salieron de conflictos y violencias (Sud África, Mozambique, Ruanda, Salvador, Honduras, Nicaragua) siguen registrando altos niveles de violencia, en algunos casos mayores a los que se vivían durante el conflicto. Ello se debe a que adicional a que no han respondido a las necesidades objetivas (eliminación de la pobreza, segregación y desigualdad) no han logrado instalar prácticas populares de respuesta a las necesidades subjetivas de la paz o sea la superación de la rabia, rencor y retaliación (3Rs). Si Colombia no desea encontrarse en la misma o peor situación de violencia dentro de 15-20 años deberá resolver este tema, trágicamente todavía poco valorado en las ciencias sociales y políticas. Familia y escuela jugarán un rol fundamental. Es allí donde la prevención gana 
toda su fuerza. Gastar un dólar en prevención ahorrará 7 dólares en intervención, dicen los expertos.

Como bien lo explica Castells (2011, p. 197), construimos nuestra realidad como reacción ante acontecimientos reales, internos y externos, que son procesados por el cerebro de acuerdo con modelos metales previamente establecidos y, desafortunadamente, en Colombia, el modelo mental preestablecido puede estar profundamente influenciado por el conflicto armado más largo del continente, con millones de víctimas, de daños morales y pecuniarios.

\section{CONSIDERACIONES FINALES}

Debido a que las emociones y las elecciones racionales son mecanismos complementarios, la evaluación inicial sobre los acontecimientos es emocional y está determinada por los marcadores somáticos que generan los sentimientos en las personas. Así, todo raciocinio siempre se verá afectado por la emoción que despierta la situación en la persona, especialmente cuando los conflictos son complejos y no existen consensos sobre las posibles causas y soluciones que deberían considerarse en un determinado periodo de tiempo.

Lo que es justo o verdadero no es absolutamente neutral u objetivo. La justicia y la verdad tiene diferentes lógicas y narraciones dependiendo de las vivencias y la posición social del actor. En momentos de transición hacia la paz, la justicia supone: “[...] la construcción y/o fortalecimiento de escenarios formales para esclarecer la verdad y para definir las formas de reparación.” Tarea en donde es fundamental la existencia de equilibrios entre los valores de paz y de justicia en el marco de un Estado Social de Derecho (BELLOSO MARTIN, 2017).

En un Proceso de Paz, es esencial que todos los actores se reconozcan como seres humanos, que merecen consideración y respeto, independientemente de las atrocidades y los errores que pudieron ser cometidos dentro del conflicto. Sentir empatía por el otro es fundamental para comprender y reconciliar a víctimas y victimarios, generando sentimientos de compasión y perdón. Es precisamente éste punto el más difícil de lograr dentro de un proceso de paz. Narváez (2013) explica ésta dificultad afirmando que la memoria vengativa dificulta el tránsito a la democracia, y solo cuando esta memoria se supera, se convierte en un acto de posicionamiento político para la víctima y en un ejercicio de inclusión democrática y humanización del ofensor.

El derecho a la verdad en el ámbito de la memoria histórica puede ser distorsionada por parte de ciudadanos que han vivido periodos de violencia, construyendo memoria petrificada y vengativa que dificulta el tránsito a la democracia. Por ello, la justicia transicional necesita de mecanismos que 
equilibren, por un lado, la necesidad de justicia, reparación y el deber de memoria para garantizar la no repetición y, por el otro, la necesidad de perdón y reconciliación para evitar la formación de procesos sociales de exclusión y de nuevas violencias que impidan la construcción de una paz estable y duradera. Por ello, es importante tener presente que "las decisiones en justicia transicional nunca son permanentes” sino que se desarrollan continuamente, pues deben soportar el escrutinio a lo largo del tiempo (LESSA, 2013, p. 217 apud BELLOSO MARTIN, 2017).

En este sentido, la metodología que se utilice para conocer la historia y la verdad por parte de los diversos actores condiciona de forma importante la forma como se respalda o se rechaza un proceso de paz. Así se tejen poco a poco las narrativas que justifican la sed de retaliación/venganza, escalando el uso de la violencia o, por el contrario, se construyen narrativas que re-signifiquen las ofensas dentro de procesos de justicia transicional, permitiendo canalizar los conflictos mediante el uso de las instituciones democráticas, que posibiliten la verdad, justicia, reparación y garantías de no repetición.

Sin embargo, es problemático verificar como el sistema político que debería respaldar el uso de las instituciones democráticas para resolver los conflictos, es usado en la práctica (por causa del marketing político), para fragmentar las sociedades impidiendo muchas veces, el dialogo y el respeto entre los diferentes actores e intereses en conflicto.

En un sistema político en donde las campañas se fundamentan en el desprestigio del otro, movilizando sentimientos de esperanza y miedo en el electorado, difícilmente las personas pueden sentir empatía por los grupos “rivales” y mucho menos bondad, compasión o perdón. El uso indiscriminado de nuevas tecnologías con evaluaciones rápidas, estridentes y parcializadas, no ayudan a la construcción de caminos de paz que permitan la reconciliación entre los diversos actores del conflicto. En nuestro concepto, dividir la sociedad entre amigos y enemigos crea estructuras mentales pre-conceptuosas que impide desde el inicio el dialogo entre grupos rivales, lo que termina fragmentando cada vez más las sociedades.

En este orden de ideas, consideramos que, para crear verdaderos caminos de paz, los colombianos debemos comprender que tras varias décadas de conflicto armado todos somos en parte víctimas y victimarios y, por tanto, debemos estar más abiertos a colocarnos en la posición de los otros, para comprender su sufrimiento, sintiendo compasión y permitiendo espacios de reconciliación y perdón que permitan la construcción conjunta de un futuro mejor para las próximas generaciones. 


\section{REFERENCIAS}

ALONSO COTO, Manuel A. \& ADELL, Angel. (2011) Marketing Político 2.0. Lo que todo candidato necesita saber para ganar las elecciones. Barcelona: Gestión 2000.

ARISTÓTELES. (1998) A Política. Tradução Roberto Leal Ferreira. São Paulo: Martins Fontes.

ARISTÓTELES. (2005) Retórica. Biblioteca de Autores Clássicos. Centro de Filosofia da Universidade de Lisboa. Lisboa: Imprensa Nacional-Casa da Moeda.

BELLOSO MARTIN, Nuria. (2017) La Justicia Transicional: ¿La renuncia de lo irrenunciable? In: Quaestio Iuris. Vol. 10, n. 01, Rio de Janeiro, p. 333-364.

BUCKINGHAM, Will et al. (2011) O Libro da Filosofia. Tradução Douglas Kim. São Paulo: Globo.

CASTELLS, Manuel. (2008) La Era de la Información. V II. Economía Sociedad y Cultura. El poder de la identidad. Traducción Carmen Martínez Gimeno. 7. ed. México: Siglo XXI.

CASTELLS, Manuel. (2011) Comunicación y Poder. Traducción María Hernández Díaz. Madrid: Ed. Alianza.

CENTRO NACIONAL DE MEMORIA HISTORICA. (2013) ¡Basta ya! Colombia: Memorias de Guerra y Dignidad. Informe General Grupo de Memoria Histórica. Bogotá: Departamento para la Prosperidad Social.

CIRNE-LIMA, Carlos. (2002) Dialéctica para principiantes. São Leopoldo: Ed. Unisinos.

CRUZ CASTILLO, Alba Lucia. (2012) La razón de las emociones formación social, política y cultural de las emociones. In: Revista Eleuthera. Vol. 6, enero-junio 2012.

DAMASIO, Antonio R. (1996) El error de Descartes. La razón de las emociones. Traducción Pierre Jacomet. Santiago de Chile: Editorial Andres Bello.

EL TIEMPO. (2014) 'Vamos a ganar con la paz' la segunda vuelta: Juan Manuel Santos. 25/05/2014. Disponible en: <https://goo.gl/32Hj1s>. Fecha de Consulta: 09/06/2015.

FALLOWS, James. (1996) Breaking the News. How the Media Undermine American Democracy. New York: Pantheon.

GARBER, Doris A. (1996) Mass Media in American Politics. 2. ed. Washington D.C.: CQ Press.

GITLIN, Todd. (1980) The Whole World is Watching: Mass Media in the Making and Unmaking of the New Left. Berkeley: University of California Press.

GOULD, D. B. (2004) Passionate political processes: Bringing emotions back into the study of social movements. En: GOODWIN, J. y JASPER, J. M. (Ed.) Rethinking social momements: structure, meanings and emotions. Lanham, Maryland: Rowman \& Littlefield Publishers. 
HACKER, Kenneth L. (1996) Missing links and the evolution of electronic democratization. Media, Culture \& Society, 18, p. 213-232.

HUETTEL, S. A. \& KRANTON, R. E. (2012). Identity economics and the brain: Uncovering the mechanisms of social conflict. Philosophical Transactions of the Royal Society B: Biological Sciences, 367(1589), p. 680-691.

JASPER, J. M. (1998) The Emotions of protest: Affective and reactive emotions in and around social movements. Sociological Forum, V. 13, 3.

KLINENBERG, Erick \& PERRIN, Andrew. (1996) Symbolic politics in the Information Age: The 1996 presidential campaign in cyberspace. Berkeley: University of California. Department of Sociology. Inédito.

LA REPÚBLICA. (2016) El No ha sido la campaña más barata y efectiva de la historia. Octubre 5 de 2016. Disponible en: <https://goo.gl/ZULVNh>. Fecha de Consulta: 07/11/2016.

LEMAITRE RIPOLL, Julieta. (2011) La paz en cuestión. La guerra y la paz en la Asamblea Constituyente de 1991. Bogotá: Universidad de los Andes.

LESSA, F. (2013) Memory and Transitional Justice in Argentina and Uruguay. Against Impunity. Nueva York: Palgrave Macmillan.

MOORE, David W. (1992) The Superpollsters: How They Measure and Manipulate Public Opinion in America. New York: Four Walls Eight Windows.

NARVÁEZ, L. (2013) Memoria y Democracia. In: Harvard Review of Latin America. Disponible en: <https://goo.gl/DxfrGq>. Fecha de Consulta: 23/04/2017.

NARVÁEZ, L. (2017) El gran reto de Colombia: Superar la cultura de la Venganza. Disponible en: <https://goo.gl/bVAXr2>. Fecha de Consulta: 23/04/2017.

NUSSBAUM, Martha C. (2017) Las emociones políticas. ¿Por qué el amor es importante para la justicia? México: Paidós, 2017.

PATTERSON, T. E. (1993) Out of order: How the decline of the Political Parties and the Growing Power of the News Media Undermine the American Way of Electing Presidents. New York: Alfred Knopf.

REVISTA SEMANA. (2014) Seis millones de víctimas deja el conflicto en Colombia. 2014/02/08. Disponible en: <https://goo.gl/hhE22X>. Fecha de Consulta: 12/06/2015.

SALAZAR, Hernando. (2014) BBC Mundo. La campaña electoral en Colombia: la "más sucia” de su historia. 19/05/2014. Disponible en: <https://goo.gl/Y75FAP>. Fecha de Consulta: 09/06/2015.

SIERRA RESTREPO, Álvaro. (2014) Y la paz decide en estas elecciones presidenciales. Revista Semana. 05/25/2014. Disponible en: <https://goo.gl/ZM0vnO>. Fecha de Consulta: 23/04/2017. 
SUNSTEIN, Cass R. (2009) Leyes de Miedo. Más allá del principio de precaución. Buenos Aires: Katz Editores.

TODOROV, S. (2000) Los Abusos de la Memoria. Barcelona: Paidós.

VALE DOS SANTOS, Moisés. (2014) Razão e emoção na arte retórica de Aristóteles. Curitiba: Ed. CRV.

VALENCIA TELLO, Diana Carolina. (2015) El Estado en la era de la globalización y las nuevas tecnologías. Bogotá: Ibañez.

Diana Carolina Valencia-Tello Profesora Principal de Derecho Administrativo de la Universidad del Rosario (Bogotá, Colombia). Especialización en Derecho Administrativo y Ambiental en Universidad del Rosario. Maestría, Doctorado y Posdoctorado en la Universidad Federal del Paraná. E-mail: dianac.valencia@urosario.edu.co 